\title{
A Systematic Study of Longwave Radiative Heating and Cooling within Valleys and Basins Using a Three-Dimensional Radiative Transfer Model
}

\author{
Sebastian W. Hoch and C. David Whiteman \\ University of Utah, Salt Lake City, Utah \\ BERNHARD MAYER \\ Meteorological Institute, Ludwig-Maximilians-University, Munich, Germany
}

(Manuscript received 19 April 2011, in final form 29 July 2011)

\begin{abstract}
The Monte Carlo code for the physically correct tracing of photons in cloudy atmospheres (MYSTIC) three-dimensional radiative transfer model was used in a parametric study to determine the strength of longwave radiative heating and cooling in atmospheres enclosed in idealized valleys and basins. The parameters investigated included valley or basin shape, width, and near-surface temperature contrasts. These parameters were varied for three different representative atmospheric temperature profiles for different times of day. As a result of counterradiation from surrounding terrain, nighttime longwave radiative cooling in topographic depressions was generally weaker than over flat terrain. In the center of basins or valleys with widths exceeding $2 \mathrm{~km}$, cooling rates quickly approached those over flat terrain, whereas the cooling averaged over the entire depression volume was still greatly reduced. Valley or basin shape had less influence on cooling rates than did valley width. Strong temperature gradients near the surface associated with nighttime inversion and daytime superadiabatic layers over the slopes significantly increased longwave radiative cooling and heating rates. Local rates of longwave radiative heating ranged between -30 (i.e., cooling) and $90 \mathrm{~K} \mathrm{day}^{-1}$. The effects of the near-surface temperature gradients extended tens of meters into the overlying atmospheres. In small basins, the strong influence of nocturnal near-surface temperature inversions could lead to cooling rates exceeding those over flat plains. To investigate the relative role of longwave radiative cooling on total nighttime cooling in a basin, simulations were conducted for Arizona's Meteor Crater using observed atmospheric profiles and realistic topography. Longwave radiative cooling accounted for nearly $30 \%$ of the total nighttime cooling observed in the Meteor Crater during a calm October night.
\end{abstract}

\section{Introduction}

Radiative cooling and heating from emission and absorption of longwave radiation are two of the processes that influence the temperature structure of the atmospheric boundary layer. The strength of radiative cooling and heating, however, is itself a result of the atmosphere's temperature structure and is, therefore, closely linked to all other processes influencing the temperature evolution of the atmosphere, including sensible heat flux divergence, horizontal and vertical advection, shortwave radiative heating, and thermal diffusion. In

Corresponding author address: Sebastian W. Hoch, University of Utah, 135 S 1460 E, Rm. 819, Salt Lake City, UT 84112.

E-mail: sebastian.hoch@utah.edu complex terrain, these processes are linked to both largeand small-scale weather phenomena such as synopticscale circulations, channeled flows, thermally driven flows, and turbulent mixing. Because there is a tight linkage between radiative cooling and heating processes and the atmospheric temperature structure, the effects of the different processes cannot readily be separated (Kondratyev 1969). Nevertheless, the momentary forcing of the thermal structure that is due to radiative effects can be calculated and can be compared with the overall temperature tendency.

Radiative heating and cooling occur when radiative energy is exchanged by differential emission and absorption among different air layers, the earth's surface, and space. In terms of radiative fluxes, flux gradients in the atmosphere result in either a divergence of the 
radiative flux and radiative cooling or in a convergence of the radiative flux and radiative heating.

Recent developments in radiative transfer modeling now allow simulations of the radiative field in complex terrain to be readily made. Photon-tracing models such as the Monte Carlo code for the physically correct tracing of photons in cloudy atmospheres (MYSTIC) now allow for a realistic representation of complex surface terrain (Mayer 2009; Mayer et al. 2010).

The role of radiative cooling within topography has previously been investigated for real basins (Kondo et al. 1989) and investigated theoretically (McKee and Whiteman 1977; Kyle 1986). Kondo et al. (1989) calculated the atmospheric heat budget for the Aizo basin in Japan, estimating the individual heat budget terms for daytime heating and nighttime cooling. Radiative cooling accounted for $20 \%$ of the total nighttime cooling of the basin atmosphere and was found to reduce daytime heating.

McKee and Whiteman (1977) calculated the receipt of radiation in different spectral bands for a surface element on the floor of an idealized valley. They showed that incoming radiation at the valley floor was enhanced relative to the no-terrain case because of the radiative contribution (back radiation) from the surrounding valley sidewalls. The result was a reduction in nighttime net radiative loss at the surface. Although they did not make calculations of radiative flux divergence, they did speculate that there were unlikely to be significant changes in cooling rates relative to flat terrain.

Kyle (1986) developed a model to calculate the radiative heating in valleys and hollows and applied it to Colorado's Brush Creek Valley (Kyle 1987). He found that radiative cooling in a $\mathrm{V}$-shaped valley with sidewall temperatures that were colder than those of the air is greater than over a flat surface and that $10 \%-20 \%$ of the nighttime heat loss in the Brush Creek Valley atmosphere occurs as a result of radiative cooling.

In this paper, we investigate radiative heating and cooling in valley and basin atmospheres using the stateof-the-art MYSTIC radiative transfer model, which accounts for the complex feedbacks between the underlying topography and the radiative field. Idealized topographies of varying size and shape are combined with typical atmospheric temperature profiles and surface temperature distributions to serve as input for the radiative transfer model. These idealized parametric simulations are focused on determining how topographies of different size and shape with different prescribed temperature profiles affect radiative transfer and atmospheric cooling rates. Comparisons are made between radiative cooling rates in valleys and basins and over plains. Calculations are first made for basin and valley atmospheres where the sidewall temperatures match air temperatures at the same elevation in the valley or basin center. In a second step, calculations are made for situations in which the sidewall surface temperatures differ from air temperatures at the same elevation in the nearby atmosphere - a situation that more closely matches reality because of the known formation of shallow superadiabatic or inversion layers over sloping surfaces. Then, to estimate the importance of longwave radiative heating and cooling, longwave radiative heating rates are simulated for the actual topography of Arizona's Meteor Crater basin during the night of 22/23 October 2006 and are compared with direct observations of the total observed temperature tendencies within the crater basin.

This paper discusses only longwave radiative transfer. Daytime shortwave radiative transfer is an important topic that can be handled by MYSTIC, which can resolve the spatially varying insolation and time-dependent shadows that occur in complex terrain areas, but its treatment is beyond the scope of this paper.

\section{Model description and setup}

\section{a. The MYSTIC $3 D$ radiative transfer model}

The MYSTIC radiative transfer model simulates radiative transfer in three-dimensional atmospheres (Mayer 2009; Mayer et al. 2010; Emde and Mayer 2007). The model, developed as a solver for the freely available libRadtran package (Mayer and Kylling 2005), handles three-dimensional clouds, inhomogeneous surface albedo, and topography. MYSTIC radiative transfer computations have been compared with those from the one-dimensional discrete ordinate radiative transfer (DISORT) code (Stamnes et al. 1988) and with other three-dimensional solvers (Cahalan et al. 2005). MYSTIC computations have also been validated against radiative flux measurements in the topographic basin of Arizona's Meteor Crater (Mayer et al. 2010). MYSTIC performs its calculations by tracking the trajectories of photons through the model domain, and it can also compute backward photon trajectories beginning at selected points on the terrain. This backward scheme reduces the number of photons that need to be tracked and greatly reduces the computational requirements necessary to make 3D calculations for selected points within a larger scene (Mayer et al. 2010). For the calculation of heating rates, we consider absorption and emission of photons. Both are evaluated as averages over three-dimensional model grid boxes rather than at levels (since we are not interested in fluxes through surfaces but rather in absorption and emission in a volume). The thermal emission of a grid box is calculated without tracing any photons, by 

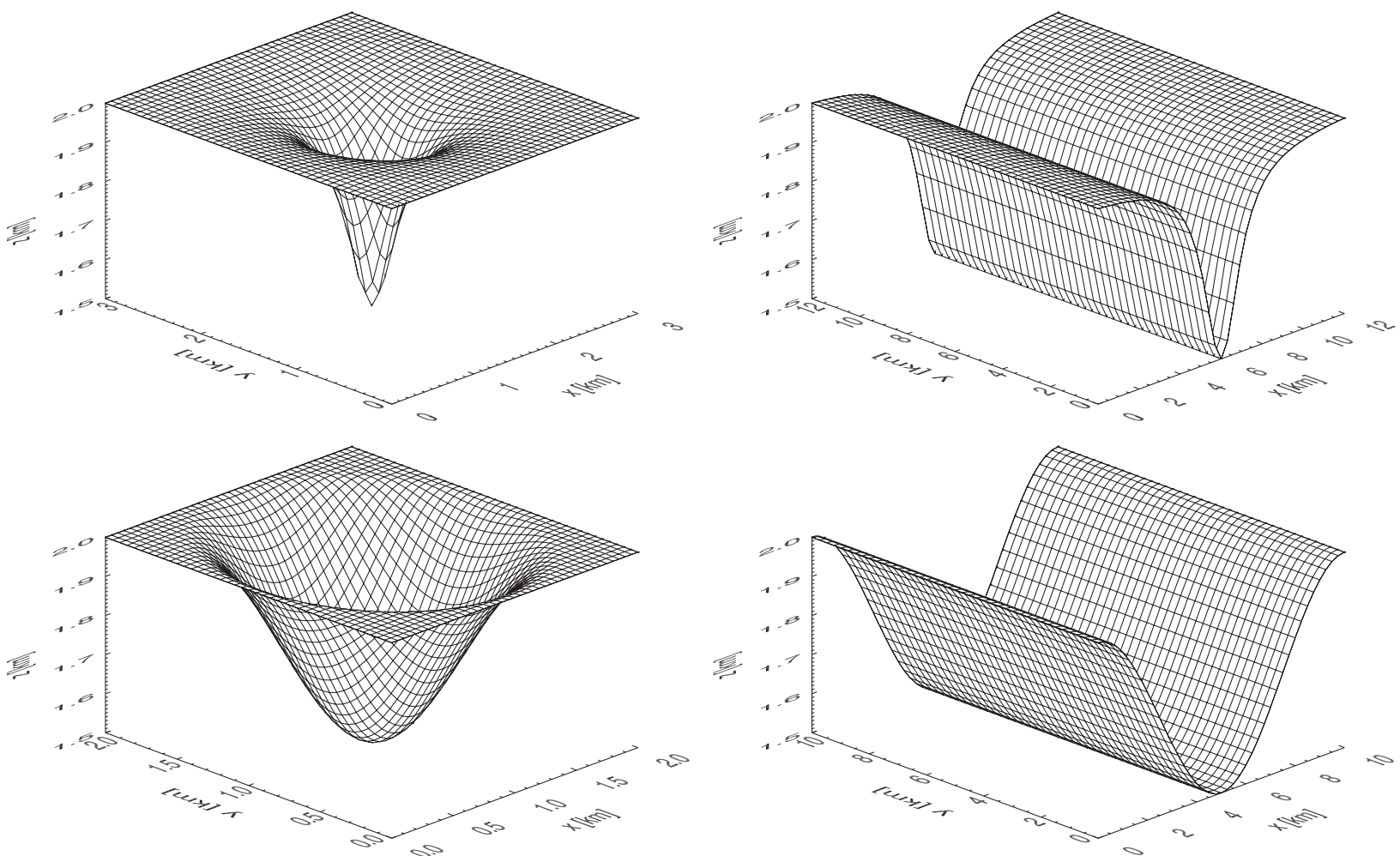

FIG. 1. Selected examples of (left) basin and (right) valley topographies based on (top) the witch-of-Agnesi function and (bottom) a sinusoidal curve. Only every fifth gridline is drawn. The width scales of the topographies vary from $0.5 \mathrm{~km}$ in the top-left panel to $5 \mathrm{~km}$ in the bottom-right panel.

determining the product of the Planck function integrated over solid angle (i.e., multiplied by $4 \pi$ ) and the vertically integrated optical thickness. To obtain the absorption, photons are started at random locations within the grid box and traced until they are absorbed; the photon weight is then simply $4 \pi$ times the Planck function evaluated for the temperature at the location of the absorption [see also Zinner et al. (2008) for a brief description of the thermal backward Monte Carlo approach]. After dividing the absorption by the number of photons started in the grid box and normalizing both quantities to the height of the grid box, the sum of both quantities gives the rate of energy absorption in the grid box in watts per cubic meter, which is readily converted to a heating rate in kelvins per day. Note that-in particular, in highly absorbing wavelength bands-absorption and emission are equally large numbers with opposite sign that nearly cancel. For that reason, large photon numbers are required to obtain good statistics. In the thermal spectral range this is not a problem, however, because the photons are usually absorbed immediately or after very few scattering events.

For complex-terrain computations, the inputs to MYSTIC include a topography dataset and a model atmosphere that is assumed to be horizontally homogenous.
Surface temperatures are normally set equal to the air temperatures at the same elevations, but an optional grid of surface temperatures can be prescribed to introduce air-surface temperature contrasts representing shallow superadiabatic or stable layers near the surface.

\section{b. Basin and valley geometries, symmetry, and computational effort}

Four idealized geometries were chosen for the computations. They resulted from the combination of the two basic types of topographic depressions, valleys and basins, with two cross sections defined mathematically using sine and witch-of-Agnesi functions. The width scales of the infinitely long valleys and the rotationally symmetric basins, defined as the width at half-depth, were varied among $0.5,1,2$, and $5 \mathrm{~km}$. The basin and valley-floor elevations were set to $1500 \mathrm{~m}$ above mean sea level (MSL) and their depths were set to $500 \mathrm{~m}$. Reference calculations were performed for a horizontal plain at $1500-\mathrm{m}$ elevation using identical atmospheric profiles. Figure 1 shows examples of the different topographies. Table 1 lists the volumes and horizontal areas at the tops of all basin topographies and of valley segments of lengths that are equal to the widths at the 
TABLE 1. Volumes and top areas of the topographies. Values for valleys represent valley segments with lengths equal to the widths at the valley tops.

\begin{tabular}{|c|c|c|c|c|c|c|c|c|}
\hline \multirow[b]{3}{*}{ Width scale (km) } & \multicolumn{4}{|c|}{ Sinusoidal } & \multicolumn{4}{|c|}{ Witch of Agnesi } \\
\hline & \multicolumn{2}{|r|}{ Basin } & \multicolumn{2}{|c|}{ Valley (segment) } & \multicolumn{2}{|r|}{ Basin } & \multicolumn{2}{|c|}{ Valley (segment) } \\
\hline & $\operatorname{Vol}\left(\mathrm{km}^{3}\right)$ & Top area $\left(\mathrm{km}^{2}\right)$ & $\operatorname{Vol}\left(\mathrm{km}^{3}\right)$ & Top area $\left(\mathrm{km}^{2}\right)$ & $\mathrm{Vol}\left(\mathrm{km}^{3}\right)$ & Top area $\left(\mathrm{km}^{2}\right)$ & $\operatorname{Vol}\left(\mathrm{km}^{3}\right)$ & Top area $\left(\mathrm{km}^{2}\right)$ \\
\hline 0.5 & 0.12 & 0.79 & 0.25 & 1 & 0.28 & 7.07 & 0.98 & 9 \\
\hline 1 & 0.47 & 3.14 & 1 & 4 & 1.11 & 28.27 & 3.92 & 36 \\
\hline 2 & 1.87 & 12.57 & 4 & 16 & 4.43 & 113.10 & 15.69 & 144 \\
\hline 5 & 11.68 & 78.54 & 25 & 100 & 27.67 & 706.86 & 98.09 & 900 \\
\hline
\end{tabular}

valley tops. Keep in mind, however, that valleys of infinite length were modeled.

All topographies were represented by a $200 \times 200$ element grid, so that the horizontal gridcell size varied with the width scale of the valley or basin. The symmetry of the terrain greatly reduced the computational requirements for these calculations. Longwave radiative heating rates were computed by tracing 5 million photons for each grid cell in a half cross section of each valley or basin and were then assigned to the volumes they represent. The Monte Carlo noise for heating rates calculated within basin and valley atmospheres was below $0.1 \mathrm{~K} \mathrm{day}^{-1}$.

\section{c. Atmospheric profiles}

Idealized temperature profiles (Fig. 2) and humidity profiles for use as atmospheric inputs to MYSTIC were constructed subjectively by scrutinizing a large set of atmospheric profiles collected in various Rocky Mountain valleys in the 1970s with a tethered-balloon sounding system (Whiteman 1980). Three basic profiles were chosen to represent typical atmospheric structures of 1) a wellmixed atmosphere [1500 local standard time (LST)], 2) an evening atmosphere with a shallow inversion of 50-m depth (1900 LST), and 3) a stable atmosphere that is typical of the presunrise hours (0600 LST). The water vapor mixing ratio was kept constant at $3.25 \mathrm{~g} \mathrm{~kg}^{-1}$ in the lowest kilometer of the model atmospheres. The atmosphere within the 500-m-deep topography was divided into 35 vertical layers, with 5 -m resolution up to $100 \mathrm{~m}, 10-\mathrm{m}$ resolution to $200 \mathrm{~m}, 50-\mathrm{m}$ resolution to $400 \mathrm{~m}$, and a 100-m layer at the top of the basin or valley atmosphere. Above the topography, the model atmosphere, with a total of 80 layers of increasing layer thickness, extended to $100 \mathrm{~km}$.

\section{d. Temperature contrasts near the surface}

The influences of the surface or ground temperature and the temperature contrast between the air and ground temperatures have been shown to be very important for computations of radiative heating and cooling rates over homogeneous terrain (Räisänen 1996; Hoch 2005; Savijärvi
2006). Therefore, we sought a way to estimate the magnitude of the air-ground temperature differences for inclusion in our radiative computations. To gain an idea of the range of surface temperature excesses and deficits over the course of a day, we used observations of coincident air and surface temperature data from seven sites in Arizona's Meteor Crater basin using the Meteor Crater Experiment (METCRAX) dataset (Whiteman et al. 2008). Table 2 lists half-hourly means of the temperature differences between the ground surface observed with infrared thermometers (Model 4000.4ZL from Everest Interscience, Inc., of Tucson, Arizona) and air temperatures observed with aspirated thermistors at $5 \mathrm{~m}$ above ground level (AGL) during calm and synoptically undisturbed periods. At 1500 LST, air-ground temperature differences were roughly $10 \mathrm{~K}$; at 1900 and 0600 LST the surface is typically about 4 and $2 \mathrm{~K}$ colder than the air at $5 \mathrm{~m}$ above the ground, respectively. Using these data for guidance, surface temperature deficits during the nighttime cases (1900 and 0600 LST) were

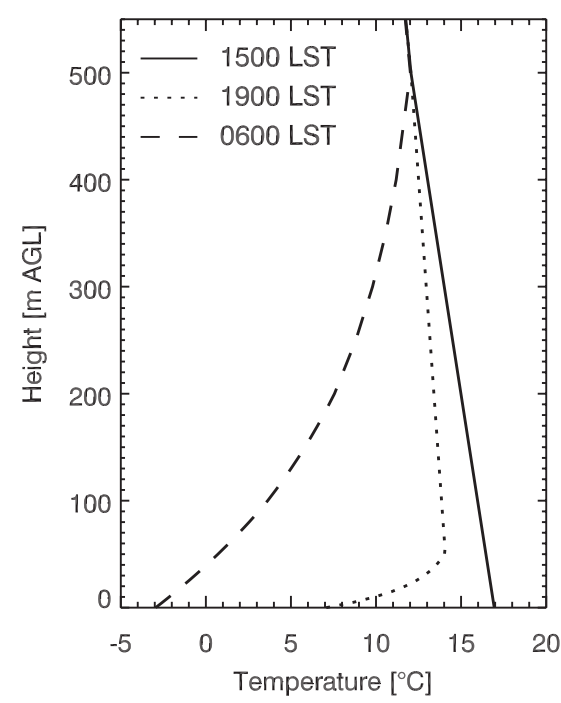

FIG. 2. Atmospheric temperature profiles used as MYSTIC input representing conditions typically found in Rocky Mountain valleys at 1500 (solid), 1900 (dotted), and 0600 (dashed) LST. 
TABLE 2. Observed half-hour-mean surface-air temperature differences $T_{\text {surf }}-T_{\text {air }}(\mathrm{K})$ centered on the times indicated for seven sites within and near Meteor Crater during selected times on two clear-sky days.

\begin{tabular}{|c|c|c|c|c|c|c|}
\hline & $\begin{array}{c}1500 \mathrm{MST} \\
22 \mathrm{Oct}\end{array}$ & $\begin{array}{c}1500 \mathrm{MST} \\
27 \mathrm{Oct}\end{array}$ & $\begin{array}{c}1900 \mathrm{MST} \\
22 \mathrm{Oct}\end{array}$ & $\begin{array}{c}1900 \mathrm{MST} \\
27 \mathrm{Oct}\end{array}$ & $\begin{array}{l}0600 \mathrm{MST} \\
23 \mathrm{Oct}\end{array}$ & $\begin{array}{l}0600 \mathrm{MST} \\
28 \mathrm{Oct}\end{array}$ \\
\hline \multicolumn{7}{|l|}{$0-5 \mathrm{~m}$} \\
\hline Upper west slope & -0.6 & -1.1 & -6.0 & -4.9 & -3.4 & -2.8 \\
\hline Lower west slope & 13.6 & 13.0 & -7.2 & -5.8 & -5 & -5.2 \\
\hline Crater floor & 11.2 & 11.6 & -4.1 & -3.9 & -3.7 & -2.8 \\
\hline Lower east slope & & 5.3 & -5.4 & -6.0 & -2.8 & -2.8 \\
\hline Upper east slope & 17.6 & 16.9 & -1.2 & -1.3 & -2.1 & -1.9 \\
\hline \multicolumn{7}{|l|}{$0-2 \mathrm{~m}$} \\
\hline Crater rim & 10.0 & 8.7 & -4.8 & -4.4 & -0.2 & 0.1 \\
\hline Plain, SW of crater & 7.0 & 5.6 & -4.3 & -3.2 & -3.5 & -2.8 \\
\hline
\end{tabular}

varied in $2-\mathrm{K}$ steps from 0 to $6 \mathrm{~K}$, and temperature excesses for the 1500 LST daytime case were varied in $5-\mathrm{K}$ steps between 0 and $15 \mathrm{~K}$.

\section{Model results}

In this section we first calculate longwave radiative heating rates for cases in which the surface temperature is the same as the air temperature. These calculations are performed for both sinusoidal- and witch-of-Agnesishaped topographies. These calculations are followed by calculations in which surface-air temperature deficits and excesses are present. This second set of calculations is limited to sinusoidal-shaped topographies to reduce the number of simulations.

\section{a. Radiative heating-rate profiles-without surface-air temperature contrasts}

\section{1) BASIN-AVERAGE RADIATIVE HEATING RATES}

The basin-average radiative heating rates for the different topographies are calculated by weighting the heating rates calculated for the different model grid boxes with respect to the volume these grid boxes represent in the topographies. Table 3 lists these basinaverage radiative heating rates calculated for the three different times of day in sinusoidal- and witch-of-Agnesishaped valleys and basins. Heating rates for a flat plain are given for comparison. The magnitudes of the basinaverage radiative heating rates were generally small, ranging from $-2.34 \mathrm{~K} \mathrm{day}^{-1}$ in a 5 -km-wide sinusoidal basin at $0600 \mathrm{LST}$ to $-1.36 \mathrm{~K} \mathrm{day}^{-1}$ in a $500-\mathrm{m}$-wide sinusoidal valley at $1500 \mathrm{LST}$. In the next section, the vertical profiles of radiative heating rates will show that radiative heating may be of greater importance locally than is suggested by the basin-average values.

For the 1500 LST reference case, a weak radiative cooling resulted from the prescribed atmospheric temperature distribution. The same temperature profile led to similar weak cooling in all modeled topographies. The maximum difference from the reference-case cooling was $12 \%$.

For the 1900 LST case, radiative cooling rates within the modeled topographies were lower than those for the flat-terrain reference case. The cooling rates in a 500-mscale basin reached only $43 \%$ of the reference case (heating rate of $-3.45 \mathrm{~K} \mathrm{day}^{-1}$ ). The total radiative cooling at 1900 LST did not depend strongly on the shape-sinusoidal or witch of Agnesi-but depended more on the size and type (i.e., valley or basin) of topographic depression. Cooling rates were weaker in smaller depressions and were weaker in basins than in valleys.

The results for the 0600 LST case were similar to those for $1900 \mathrm{LST}$, but the reduction in the total radiative cooling rate relative to the flat-terrain case was not quite

TABLE 3. Basin- and valley-average radiative heating rates $\left(\mathrm{K} \mathrm{day}^{-1}\right)$ for 500-m-deep sinusoidal-shaped (sine) and witch-of-Agnesishaped (Agn) valleys and basins of different width scales, and for flat terrain. Listed are simulations for the three different times. No airsurface temperature differences were prescribed.

\begin{tabular}{|c|c|c|c|c|c|c|c|c|c|c|c|c|c|c|c|}
\hline \multirow[b]{3}{*}{ Widths } & \multicolumn{5}{|c|}{$1500 \mathrm{LST}$} & \multicolumn{5}{|c|}{1900 LST } & \multicolumn{5}{|c|}{0600 LST } \\
\hline & \multicolumn{2}{|c|}{ Basin } & \multicolumn{2}{|c|}{ Valley } & \multirow[t]{2}{*}{ Flat } & \multicolumn{2}{|c|}{ Basin } & \multicolumn{2}{|c|}{ Valley } & \multirow[t]{2}{*}{ Flat } & \multicolumn{2}{|c|}{ Basin } & \multicolumn{2}{|c|}{ Valley } & \multirow[t]{2}{*}{ Flat } \\
\hline & Sine & Agn & Sine & Agn & & Sine & Agn & Sine & Agn & & Sine & Agn & Sine & Agn & \\
\hline $500 \mathrm{~m}$ & -1.38 & -1.56 & -1.36 & -1.48 & -1.41 & -1.50 & -1.64 & -1.77 & -1.76 & -3.45 & -1.88 & -1.97 & -2.07 & -2.11 & -2.59 \\
\hline $1 \mathrm{~km}$ & -1.47 & -1.56 & -1.43 & -1.49 & -1.41 & -1.60 & -1.66 & -1.89 & -1.83 & -3.45 & -2.06 & -2.03 & -2.22 & -2.21 & -2.59 \\
\hline $2 \mathrm{~km}$ & -1.49 & -1.58 & -1.46 & -1.50 & & -1.64 & -1.65 & -1.94 & -1.84 & -3.45 & -2.17 & -2.05 & -2.31 & -2.24 & -2.59 \\
\hline $5 \mathrm{~km}$ & -1.50 & -1.56 & -1.46 & -1.50 & -1.41 & -1.66 & -1.67 & -1.95 & -1.85 & -3.45 & -2.19 & -2.06 & -2.34 & -2.25 & -2.59 \\
\hline
\end{tabular}


as large. In a $500-\mathrm{m}$-wide sinusoidal basin, only $73 \%$ of the flat-plain cooling (heating rate of $-2.59 \mathrm{~K} \mathrm{day}^{-1}$ ) was reached. A $5-\mathrm{km}$-scale valley experienced $90 \%$ of the reference radiative cooling rate. A smaller depression showed weaker cooling rates than did a larger one, and the cooling rates were weaker in the basin than in the valley atmosphere.

\section{2) HeAting RATES IN VALLEY AND BASIN CENTERS AND LAYER-AVERAGED HEATING RATES}

If one were to estimate radiative heating rates in a topographic depression using a traditional one-dimensional radiative transfer model, the atmospheric profile from the basin center would be used as model input. Nighttime cooling rates in depressions have previously been addressed with this approach, neglecting all interactions between the radiative field and topography (Whiteman et al. 2002). In our simulations, the reference flat-terrain model calculations represent this approximation. The simulations presented here allow a comparison among 1) layer-averaged radiative heating-rate profiles representing the entire basin or valley, 2) heating-rate profiles calculated for the center of the depression, and 3) heatingrate profiles for corresponding flat-terrain reference cases. Figure 3 shows such a comparison for the 1900 LST case.

Radiative cooling in topographic depressions is reduced by counterradiation from the sidewalls. This is illustrated for the 1900 LST simulation in Fig. 3. With a widening of the topography, the radiative heating-rate profile in the valley or basin center approaches that for flat terrain, as expected (Fig. 3, top). The cooling rates near the top of the shallow inversion at 1900 LST are weakest for the 500-m-wide basin, followed by the 500 -m-wide valley. The cooling rates in the centers of valleys and basins that are wider than $2 \mathrm{~km}$ are almost identical to the flat-terrain case. The layer-averaged radiative cooling rates (Fig. 3, bottom), however, show the strong influence of basin width affecting the basinwide radiative cooling, which is significantly reduced even in the 5 - $\mathrm{km}$-wide valley. The importance of the differences between valley and basin topographies is visualized in Fig. 3, showing that the cooling rates in a basin are always smaller than in a valley, independent of the width of the depressions. In the 1900 LST case, maximum cooling occurs at the inversion top. In basins this maximum cooling is reduced to only one-half, and in valleys to about $70 \%$, of the cooling seen over flat terrain.

These calculations successfully demonstrate the influence of topography on radiative cooling-rate profiles in valleys and basins. The differences between the radiative heating-rate profile for layer averages and basin centers show that the use of one-dimensional radiative transfer models to calculate radiative cooling rates in topographic depressions can lead to large overestimations of basinwide radiative cooling rates.

\section{b. Effects of surface-air temperature contrasts}

\section{1) PARAMETRIC STUDY FOR FLAT TERRAIN AND 1-KM-WIDE VALLEYS AND BASINS}

It is often the case that the radiating temperature of the ground differs from that of the overlying air. Radiative cooling and heating are strongly dependent on the temperature excess of the ground surface with respect to the atmosphere during daytime and the temperature deficit of the surface under stable conditions during the evening and night. This is illustrated for flat terrain in Fig. 4, which shows the modeled radiative heating-rate profiles for the 1500, 1900, and 0600 LST atmospheres for different values of surface-air temperature contrasts. For the evening and nighttime simulations, the surface temperature was reduced by 2,4 , and $6 \mathrm{~K}$ with respect to the atmospheric temperature. For the daytime simulations, the surface temperature was elevated by 5,10 , and $15 \mathrm{~K}$. The influence of the surface-air temperature discontinuity on the radiative heating of the atmosphere during daytime is remarkable: heated surfaces led to strong heating to heights well above $50 \mathrm{~m}$ above the surface. An increased near-surface temperature deficit in the evening and at night led to enhanced near-surface cooling. Near-surface heating occurred in the lowest meters when the surface and air temperatures were equal, and a strong near-surface cooling resulted when a temperature deficit was present.

The influence of surface temperature excesses and deficits on radiative heating and cooling rates within a 1-km-wide basin is illustrated in Fig. 5. For these simulations, a grid of surface temperatures warmer or colder than the atmospheric temperatures at the same heights was prescribed. The figure panels show that, like the flatterrain case in Fig. 4, radiative heating rates change significantly within topographic depressions, especially in the near-surface air, when a strong surface temperature excess or deficit is introduced. Because more of the atmosphere inside a topographic depression is adjacent to a surface, the overall change in the heating rate of the depression is enhanced.

A layer of strong radiative heating is introduced over an overheated $(10 \mathrm{~K})$ slope in the $1500 \mathrm{LST}$ case when compared with the case with no surface-air temperature contrast (Fig. 5a vs Fig. 5c). Similar to the changes introduced by surface temperature excesses in the flatterrain case seen in Fig. 4, the weak daytime cooling in the basin at 1500 LST changes to a strong radiative 


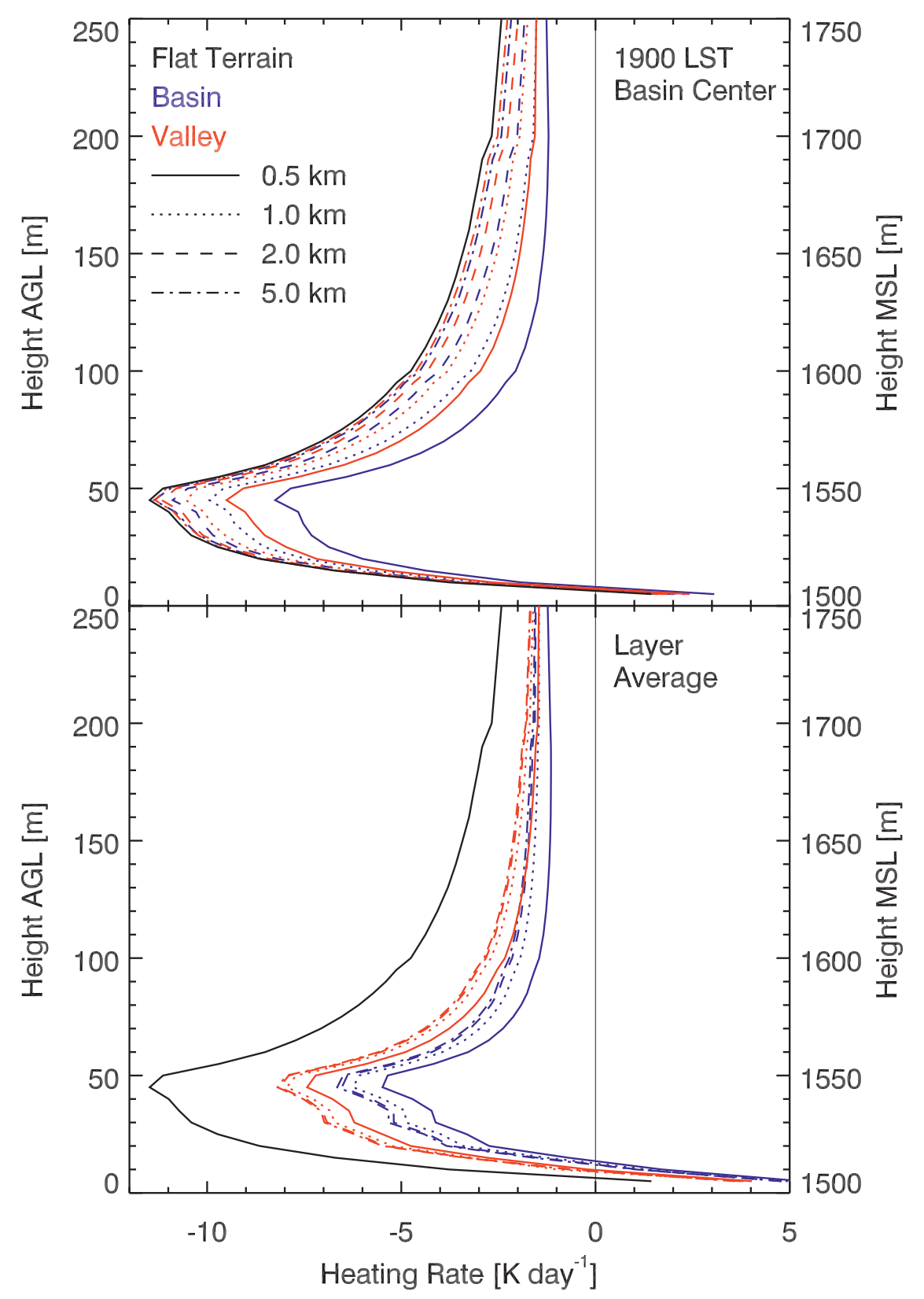

FIG. 3. Modeled longwave radiative heating-rate profiles for the different 500-m-deep sinusoidal topographies. (top) Profiles at the centers of the basins and valleys; (bottom) layeraveraged profiles. The black curves show profiles over flat terrain. Colors mark the topography type: red is valley and blue is basin. Line types denote the width scales of the basins and valleys.

heating, with extreme heating values occurring near the basin sidewalls when an overheated surface is introduced. The right-hand-side curves of Figs. 5a-d show basin-center and layer-averaged heating-rate profiles together with the profiles for the reference flat-terrain case. Radiative heating in the basin with the surface temperature excess is greater than that seen over flat terrain. The heating that is concentrated along the sidewalls leads to a larger layer-averaged heating rate than was calculated for the basin center.

When a surface temperature deficit is introduced over slopes in the evening and morning hours, radiative cooling of the valley and basin atmospheres is greatly enhanced. Layers with strong radiative cooling rates occur over the basin sidewalls for the 1900 LST simulation with a 6-K colder ground as compared with the 

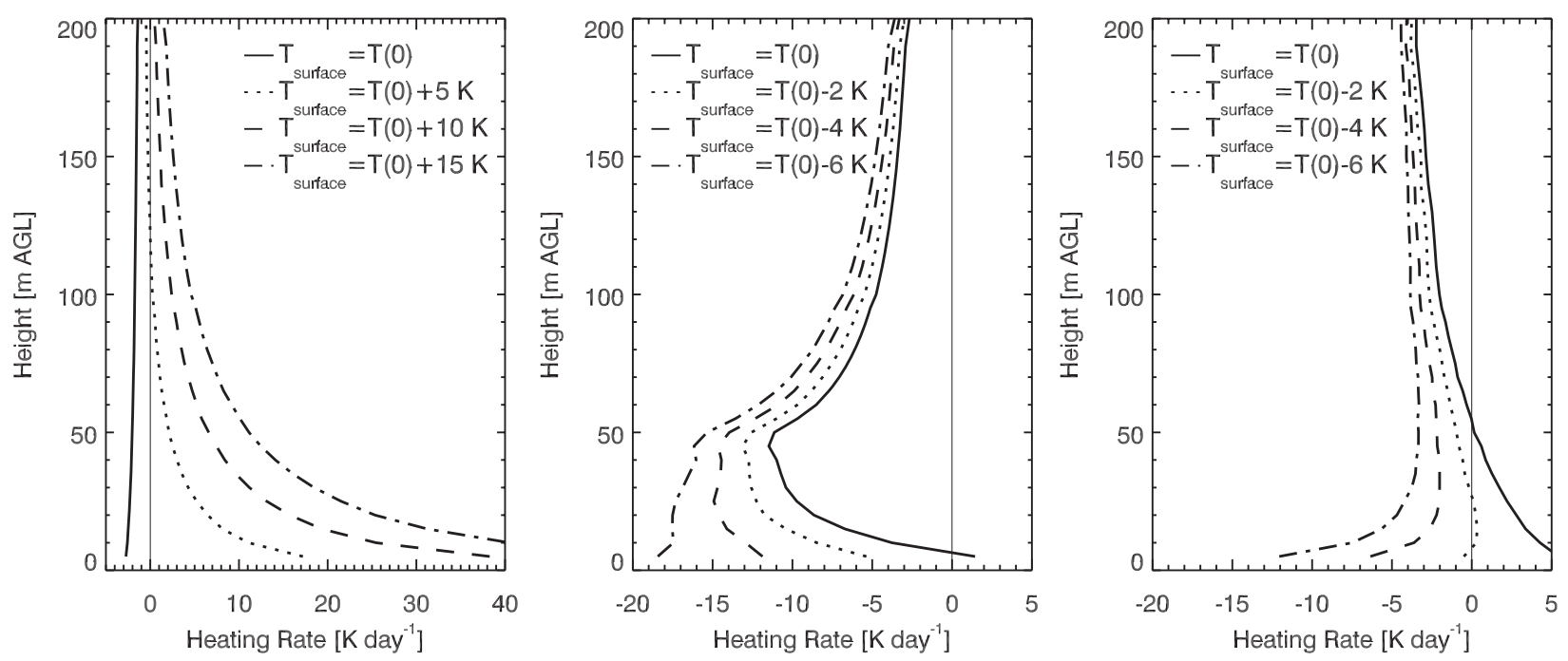

FIG. 4. Heating-rate profiles over flat terrain for (left) 1500, (center) 1900, and (right) 0600 LST. The different curves represent variations in the surface-air temperature contrast, as shown in the legends.

case with no surface temperature deficit (Fig. 5b vs Fig. 5d). A shift from a weak warming to a very strong cooling in the lowest $10 \mathrm{~m}$ is similar to the changes seen over flat terrain (Fig. 4). Whereas the cooling in the simulation without a surface-air temperature deficit was larger for the flat-terrain case and in the center of the basin, the strong cooling near the basin sidewalls introduced by the surface-air temperature deficit now leads to a layeraveraged cooling that is greater than the cooling in the basin center. a)

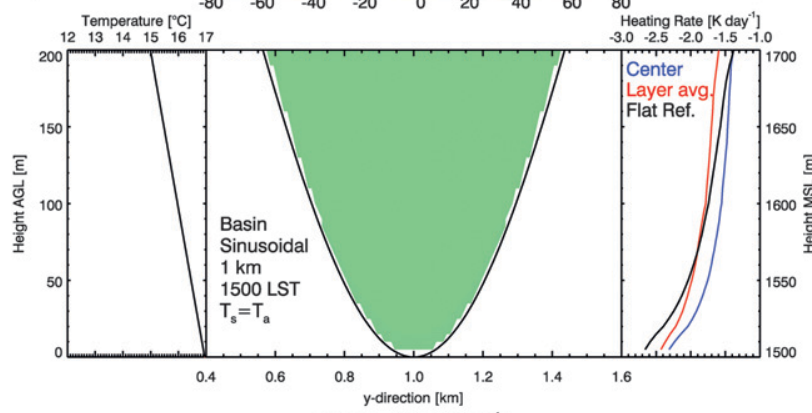

c)

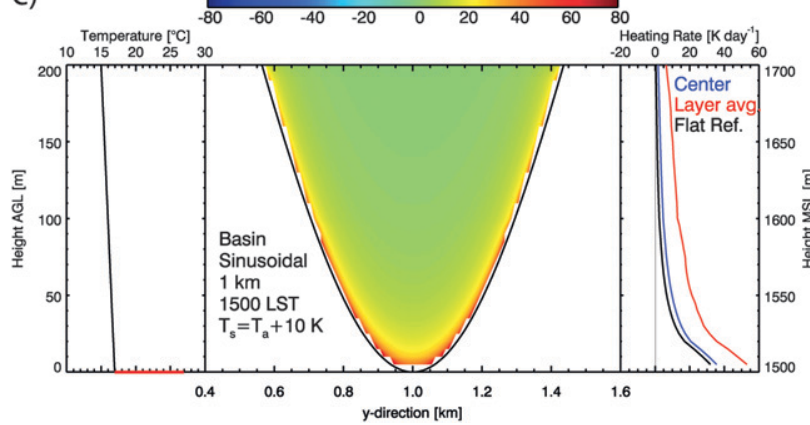

b)
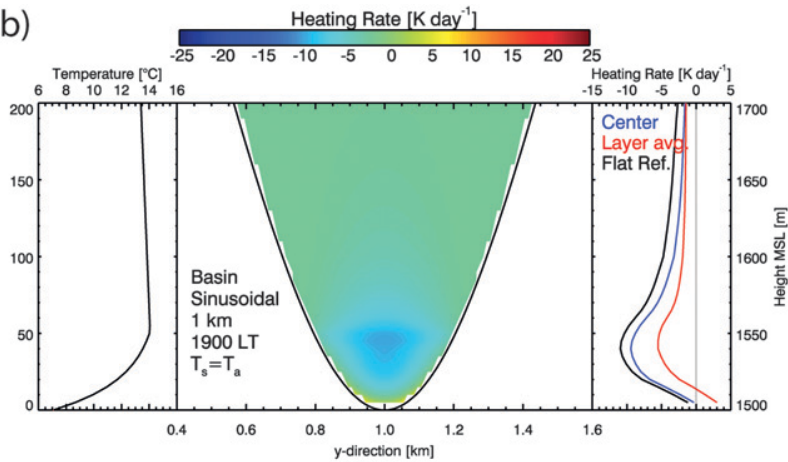

d)

Heating Rate [K day ${ }^{-1}$ ]

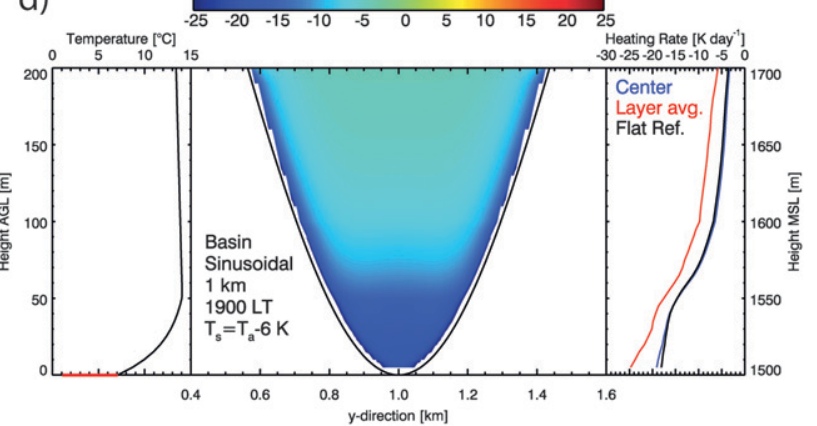

FIG. 5. Plots showing heating rates on cross sections through the lowest $200 \mathrm{~m}$ of 500-m-deep sinusoidal basins of 1-km width: (a) 1500 LST simulation without surface-air temperature contrast, (b) as in (a) but at 1900 LST, (c) 1500 LST simulation with the surface being $10 \mathrm{~K}$ warmer than the air, and (d) 1900 LST simulation with the surface being $6 \mathrm{~K}$ colder than the air. Temperature profiles are given to the left of each plot; heating-rate profiles (layer average is red, center profile is blue, and reference flat-terrain case is black) are shown to the right. 
TABLE 4. Valley- and basin-average radiative heating rates $\left(\mathrm{K} \mathrm{day}^{-1}\right)$ for 500 -m-deep sinusoidal valleys and basins of 1 -km-width scale and for flat terrain, calculated for the three different times and for different air-surface temperature excesses or deficits $(\Delta T)$.

\begin{tabular}{|c|c|c|c|c|c|c|c|c|c|c|c|c|}
\hline \multirow[b]{2}{*}{$\Delta T(\mathrm{~K}):$} & \multicolumn{4}{|c|}{$1500 \mathrm{LST}$} & \multicolumn{4}{|c|}{1900 LST } & \multicolumn{4}{|c|}{0600 LST } \\
\hline & 0 & 5 & 10 & 15 & 0 & -2 & -4 & -6 & 0 & -2 & -4 & -6 \\
\hline Flat terrain & -1.41 & 0.48 & 2.44 & 4.50 & -3.45 & -4.08 & -4.73 & -5.35 & -2.59 & -3.15 & -3.71 & -4.27 \\
\hline Valley & -1.43 & 1.04 & 3.64 & 6.37 & -1.89 & -2.81 & -3.72 & -4.60 & -2.22 & -3.06 & -3.87 & -4.67 \\
\hline Basin & -1.47 & 1.33 & 4.27 & 7.34 & -1.60 & -2.65 & -3.69 & -4.70 & -2.06 & -3.03 & -4.01 & -4.95 \\
\hline
\end{tabular}

The effects of different surface-air temperature deficits and excesses on the average radiative heating rates within the lowest $500 \mathrm{~m}$ over a flat plain and within 500-m-deep sinusoidally shaped valleys and basins of 1-km-width scale are provided in Table 4 and visualized in Fig. 6. For the daytime (1500 LST) simulation with the surface warmer than the air, the basin-average heating rate tends to increase linearly with the surface temperature excess. The basin-average heating rate in the basin increases about 1.5 times as much as the heating in the flat-terrain case. Sensitivities are 0.58, 0.53, and $0.4 \mathrm{~K} \mathrm{day}^{-1} \mathrm{~K}^{-1}$ for basin, valley, and flat-plain topographies, respectively.

For the evening (1900 LST) simulations with no nearsurface temperature deficit, less cooling is seen in valleys and basins than over flat terrain because the incoming radiation is enhanced by the surrounding topography. When a temperature deficit is established near the surface, however, radiative cooling within the topography increases and the differences in radiative cooling between the flat-terrain reference case and the $1-\mathrm{km}$ width-scale basin and valley are reduced. The valley- or basin-average heating rates vary linearly with the strength of the temperature deficit. Cooling in the basin has the largest sensitivity to the surface temperature deficit $\left(0.52 \mathrm{~K} \mathrm{day}^{-1} \mathrm{~K}^{-1}\right)$, surpassing the sensitivity for the valley $\left(0.45 \mathrm{~K} \mathrm{day}^{-1} \mathrm{~K}^{-1}\right)$ and the flat plain $\left(0.31 \mathrm{~K} \mathrm{day}^{-1} \mathrm{~K}^{-1}\right)$. When the temperature deficit at 1900 LST exceeds $5 \mathrm{~K}$, radiative cooling in the basin becomes larger than in the valley (Fig. 6, center).

The morning (0600 LST) simulations are illustrated in the right-hand panel of Fig. 6 . When the temperature deficit exceeds $2.5 \mathrm{~K}$, radiative cooling in a basin becomes stronger than in a valley or over flat terrain. If the deficit is lower than this threshold, less cooling occurs in 1-km-width basins and valleys than over flat terrain. This shows that near-surface cooling introduced by surface temperature deficits can become dominant for basin-average radiative cooling — an effect that is further discussed in section 5 .

\section{2) EFFECT OF BASIN SIZE AND SHAPE WITH FIXED AIR-SURFACE TEMPERATURE CONTRAST}

Simulations for flat terrain and 1-km-wide topographies show the importance of realistically representing surface temperature deficits and excesses in calculations of radiative heating rates in valleys and basins. The differences in basin-averaged heating rates that arise from the surface-air temperature differences are generally greater than the differences seen from variations in basin size that were investigated in section 3a. Thus, basin-average radiative heating rates were recalculated for the three times of day $(1500,1900$, and 0600 LST)
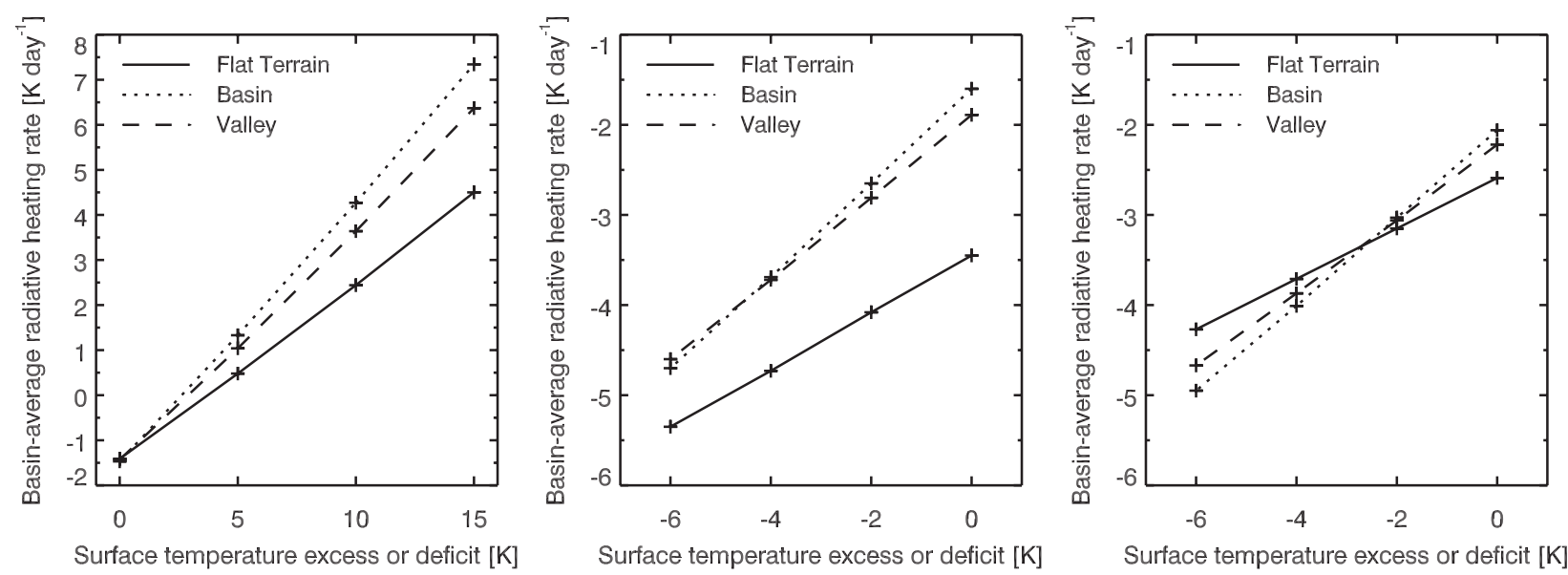

FIG. 6. Basin- and valley-average total radiative heating rates in 500-m-deep sinusoidally shaped depressions of 1-km scale as a function of temperature excess or deficit at the surface-air interface for (left) 1500, (center) 1900, and (right) 0600 LST. 
TABLE 5. Basin- and valley-average radiative heating rates $\left(\mathrm{K} \mathrm{day}^{-1}\right)$ for $500-\mathrm{m}$-deep sinusoidal valleys and basins of different width scales and for flat terrain, calculated for three different times and for representative air-surface temperature differences on the basis of observations near Meteor Crater.

\begin{tabular}{|c|c|c|c|c|c|c|c|c|c|}
\hline \multirow[b]{2}{*}{ Widths } & \multicolumn{3}{|c|}{1500 LST (10 K) } & \multicolumn{3}{|c|}{$1900 \mathrm{LST}(-4 \mathrm{~K})$} & \multicolumn{3}{|c|}{$0600 \operatorname{LST}(-2 \mathrm{~K})$} \\
\hline & Basin & Valley & Flat & Basin & Valley & Flat & Basin & Valley & Flat \\
\hline $500 \mathrm{~m}$ & 6.81 & 5.46 & 2.44 & -4.49 & -4.23 & -4.73 & -3.27 & -3.18 & -3.15 \\
\hline $1 \mathrm{~km}$ & 4.27 & 3.65 & 2.44 & -3.69 & -3.72 & -4.73 & -3.03 & -3.06 & -3.15 \\
\hline $2 \mathrm{~km}$ & 3.33 & 3.00 & 2.44 & -3.40 & -3.53 & -4.73 & -2.97 & -3.01 & -3.15 \\
\hline $5 \mathrm{~km}$ & 2.97 & 2.77 & 2.44 & -3.28 & -3.47 & -4.73 & -2.95 & -3.00 & -3.15 \\
\hline
\end{tabular}

and the different topography widths using typical airsurface temperature differences as observed in the Meteor Crater. Keep in mind, however, that these observations may not be representative for all valley and basin sizes and shapes. Table 5 lists the valley- and basin-average radiative heating rates calculated using the observed surface-air temperature deficits, as well as those for a reference flat-terrain simulation. These values can be compared with those values in Table 3 for which no airsurface temperature differences were prescribed. Figure 7 illustrates basin-average radiative heating as a function of topography size for the three times of day including the effects of a realistic surface-air temperature contrast.

For the 1500 LST case, with the surface being $10 \mathrm{~K}$ warmer than the air above, radiative heating is greater in all topographies when compared with flat terrain. The heating in the $500-\mathrm{m}$ basin reaches almost $280 \%$ of the heating seen over flat terrain. The smallest increase is seen in the $5-\mathrm{km}$ valley where radiative heating is increased by only $14 \%$.

For the 1900 LST case, with a 4-K temperature deficit, basin-average radiative cooling remains below the values seen over flat terrain. The reduction, however, is less than that seen without a temperature deficit, with the largest reduction of $31 \%$ (instead of $52 \%$ without deficit) in the $5-\mathrm{km}$ basin and the smallest reduction in cooling of $5 \%$ in the $500-\mathrm{m}$ basin (instead of a $57 \%$ reduction).

For the 0600 LST case (2-K deficit), basin-average radiative cooling stays within $6 \%$ of the reference cooling. Cooling is slightly enhanced in the $500-\mathrm{m}$-scale topographies instead of being reduced as in the no-deficit case. All other topographies see a slight reduction in cooling rates, but well below those seen in the case with no surface-air temperature contrast.

The radiative heating rates for the 1500 LST case in Fig. 7a approach the flat-terrain case as the valley and basin widths increase, as expected. This is not the case for the 1900 and 0600 LST simulations in Figs. 7b and 7c, however, because of the competing effects on the basinaverage heating rates of the radiative cooling associated with the inversion top at $50 \mathrm{~m}$ AGL (1900 LST) or deep stable stratification (0600 LST) on one hand, and the radiative cooling associated with the air-surface temperature deficit near the ground on the other. This interesting aspect of the simulations is addressed more fully in the discussion section (section 5).
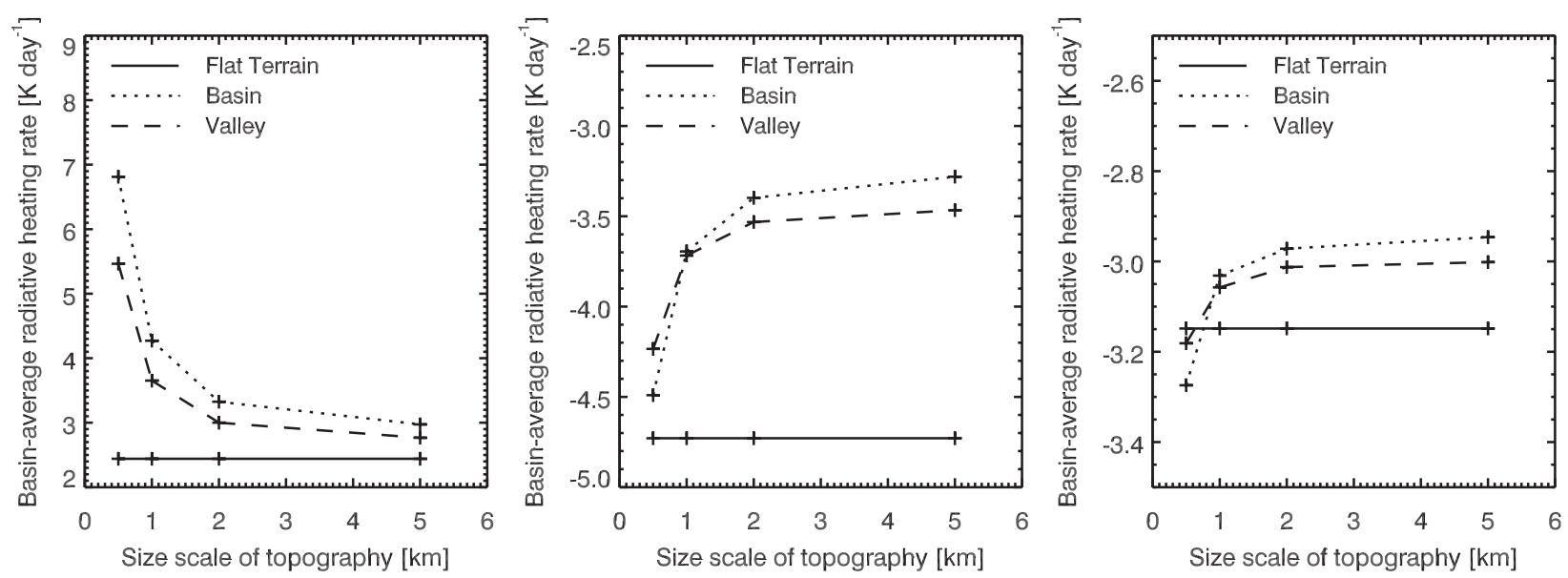

FIG. 7. Basin- and valley-average longwave radiative heating rates in 500-m-deep sinusoidally shaped depressions as a function of basin or valley size. Shown for comparison are heating rates for the same atmospheric profiles over flat terrain. Typical surface-air temperature differences at the surface-air interface were (left) $10 \mathrm{~K}$ for $1500 \mathrm{LST}$, (center) $-4 \mathrm{~K}$ for $1900 \mathrm{LST}$, and (right) $-2 \mathrm{~K}$ for $0600 \mathrm{LST}$. 


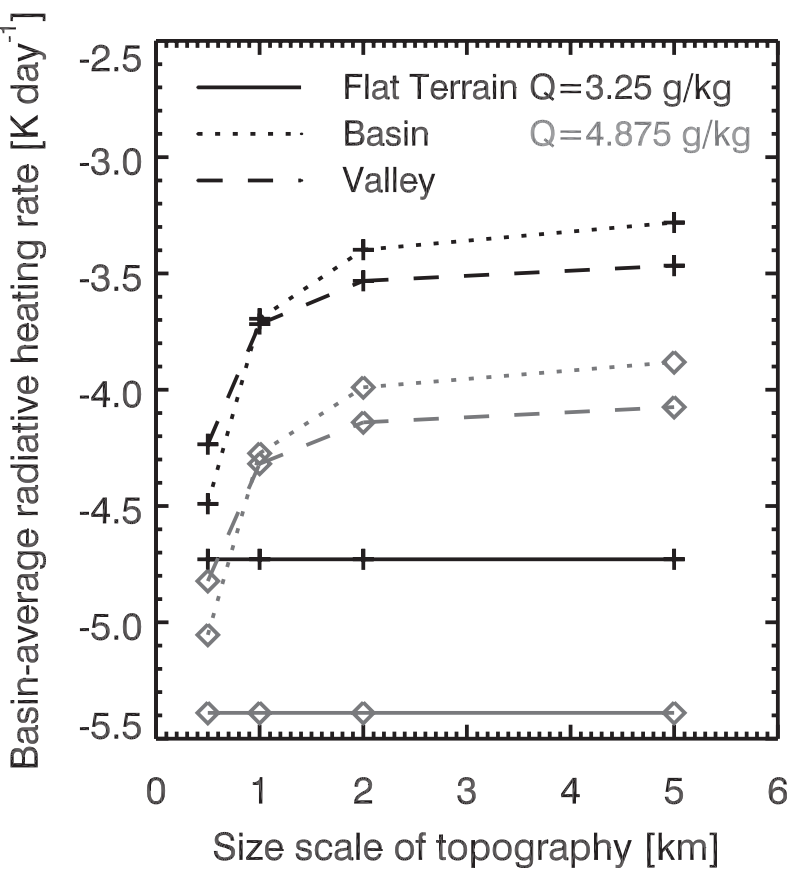

FIG. 8. Basin- and valley-average longwave radiative heating rates in 500-m-deep sinusoidally shaped depressions as a function of basin or valley size for the 1900 LST atmospheric profiles. Typical surface-air temperature deficits of $4 \mathrm{~K}$ at the surface-air interface were taken into account. The effect of a change in water vapor mixing ratio from 3.25 (black) to 4.875 (gray) $\mathrm{g} \mathrm{kg}^{-1}$ is illustrated.

\section{c. Humidity}

Water vapor, as a strong absorber, has a strong influence on longwave radiative heating rates in the atmosphere. To simplify the parametric simulations, humidity was kept constant at a mass mixing ratio of $3.25 \mathrm{~g} \mathrm{~kg}^{-1}$. This relatively low value was chosen to avoid saturation in the 0600 LST atmospheric profile. To estimate the influence of humidity on the results reported above, calculations for the reference cases with a realistic air-surface temperature contrast were performed while varying the water vapor mass mixing ratio by $\pm 50 \%$. The reduction to $1.625 \mathrm{~g} \mathrm{~kg}^{-1}(-50 \%)$ led to changes in the radiative heating rates within the lowest $500 \mathrm{~m}$ of the atmosphere of $+10 \%$ (1500 LST) and a decrease in radiative cooling of $15 \%$ (1900 LST) and 18\% (0600 LST). An increase to $4.875 \mathrm{~g} \mathrm{~kg}^{-1}(+50 \%)$ decreases the daytime (1500 LST) heating by $17 \%$ and increases the nighttime cooling rates at 1900 and 0600 LST by $14 \%$ and $18 \%$, respectively.

Figure 8 illustrates the influence of humidity changes on radiative heating and cooling in valleys and basins of different sizes for the 1900 LST case with a 4-K surface temperature deficit. A $50 \%$ increase in water vapor mass mixing ratio from 3.25 to $4.875 \mathrm{~g} \mathrm{~kg}^{-1}$ significantly increases the radiative cooling rates but does not change the general variation of the radiative cooling rates with respect to topographic shape and size.

\section{Radiative cooling in Arizona's Meteor Crater}

The three-dimensional simulations of radiative heating rates in the different idealized topographies of section 3 focused on the impact of basin size, topography type (basin or valley), and near-surface temperature structure on the radiative heating rates in valleys and basins. What, however, is the relative importance of longwave radiative cooling and heating rates with respect to the total heating rates or temperature tendencies observed within basins? To address this question, radiative heating rates within Arizona's Meteor Crater are modeled with MYSTIC and are compared with temperature tendencies observed with a sequence of temperature soundings within the crater basin. The observed temperature tendencies include the heating and cooling contributions of all processes, both short- and longwave radiative heating, advection, sensible and latent heat flux divergence, and thermal diffusion.

\section{a. Night of 22/23 October 2006 at Arizona's Meteor Crater}

The development of the stable nocturnal boundary layer in and outside Meteor Crater was studied during METCRAX. A map of the crater topography is shown in Figs. 9a and 9b. The night of 22/23 October 2006 was one of the calmest and synoptically least disturbed nights with extensive observations during the field campaign. For our simulations, atmospheric inputs for MYSTIC were compiled from detailed temperature structure data collected at meteorological towers (see Fig. 9b) and from tethersondes and radiosondes. The various meteorological instruments and measurements have been previously described by Whiteman et al. (2008).

The 22/23 October 2006 nighttime development of the crater atmosphere is summarized in Fig. 10. Strong cooling at the crater floor started around 1730 mountain standard time (MST). A strong surface inversion was soon formed, while the temperature differences in the upper part of the crater basin remained modest. Around midnight, the crater atmosphere was disturbed by a strong cold-air intrusion (Whiteman et al. 2010; Haiden et al. 2011). The intruding air disturbed the strong cold-air pool at the crater bottom, which led to a sudden rise of temperature in the lower parts of the basin and a rise in wind speed at the crater floor (Fig. 10). After this disturbance, the cooling continued and showed no major interruption of the strong surface inversion until sunrise. 

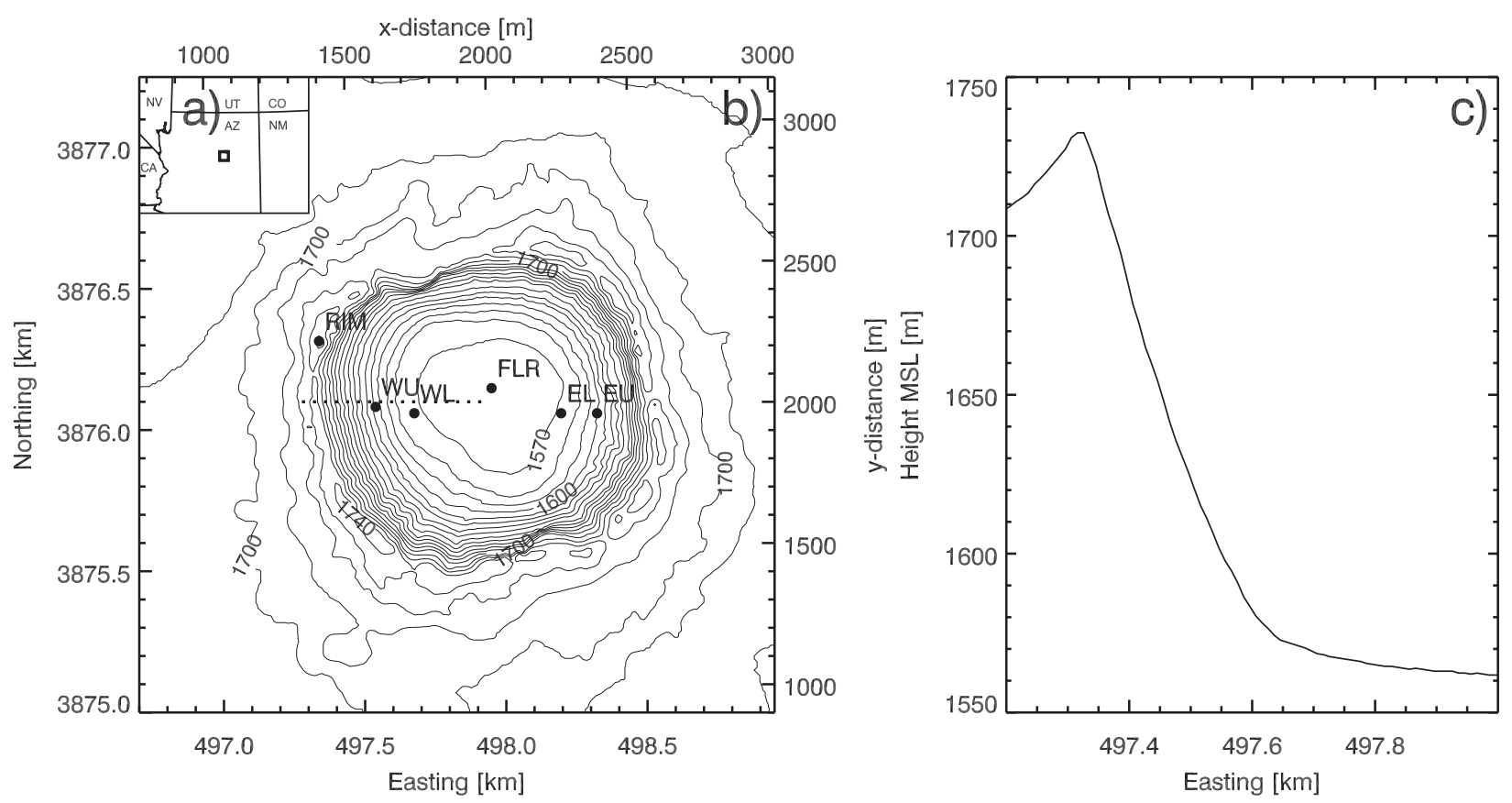

FIG. 9. (a) Location of Meteor Crater in Arizona. (b) Map of Meteor Crater (10-m contours) showing the locations of meteorological towers at the crater rim (RIM), crater floor (FLR), and the lower and upper stations on the western (WL, WU) and eastern (EL, EU) sidewalls. Secondary axes indicate the coordinates of the MYSTIC calculation domain. The dashed line and (c) show the cross-basin transect along which radiative heating rates were calculated.

\section{b. Model input for crater simulations from the METCRAX dataset}

MYSTIC was run on a $4 \mathrm{~km} \times 4 \mathrm{~km}$ domain, with a cell spacing of $10 \mathrm{~m}$ and periodic boundary conditions. The secondary axes in Fig. 9b indicate the position of the crater in the model domain. Radiative heating rates were calculated with MYSTIC along the half-transect through the crater basin indicated by the dashed line in Fig. 9b and shown in Fig. 9c. The full 3D Meteor Crater topography (Fig. 9b) was used in the model calculations for the half-transect but, to save computational time, the basin-average radiative cooling was then determined by weighting the radiative heating rates calculated for the transect grid boxes with the volume they represent in a circularly symmetric crater. The axially symmetric basin is a close approximation to the actual crater shape.

Atmospheric temperature and humidity profiles were constructed for every hour by combining observations from the meteorological tower at the crater floor (FLR) with time-interpolated tethersonde soundings from the crater floor and time-interpolated radiosonde soundings flown at 3-h intervals outside the crater basin. For levels above the maximum altitudes reached by the radiosondes (approximately $20 \mathrm{~km}$ ), a midlatitude summer standard atmosphere was added. The vertical resolution of the input atmospheric dataset was $5 \mathrm{~m}$ within the crater basin. The temperature tendency or craterwide total cooling rate resulting from all processes involved in the thermal evolution of the crater atmosphere was calculated from the hourly rate of change of temperature expressed by the consecutive temperature profiles weighted with the volume-height relationship for the crater. This involved an implicit assumption that the crater atmosphere is approximately horizontally homogeneous during stable nighttime conditions-an assumption that is supported by previous investigations using multiple tethersondes in the crater (Whiteman et al. 2008). Nighttime near-surface inversions and daytime superadiabatic layers were introduced by prescribing a surface temperature grid. The strength of the temperature excess or deficit was determined as the mean difference between the 5-m air temperature and the infrared thermometer observations at the six sites shown in Fig. 9b.

\section{c. Results for Meteor Crater}

The results from the MYSTIC simulations for Meteor Crater during 22/23 October 2006 are summarized in Table 6 and Fig. 11. Table 6 gives the basin-average heating rates or temperature tendencies observed in the crater and the percentage of this observed heating rate accounted for by the simulated longwave radiative heating rate. Figure 11 gives information on the vertical 


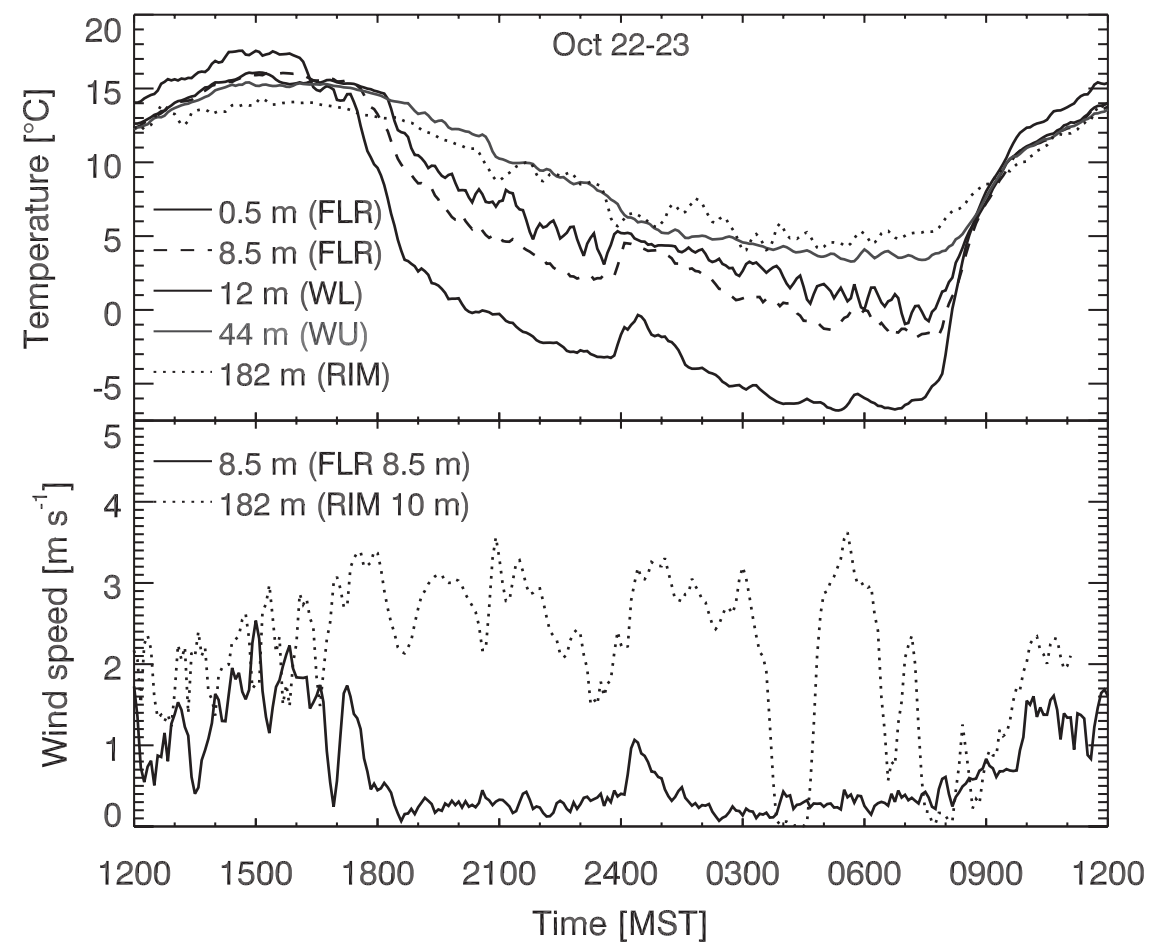

FIG. 10. Meteogram showing temperature and wind speed time series at selected sites for the night of 22/23 Oct 2006. Heights in the legend are relative to the base of the crater $(1563 \mathrm{~m}$ MSL).

distribution of total and radiative cooling rates for selected times.

The modeled radiative cooling rate contribution to the overall temperature tendency varied between $10 \%$ and $75 \%$ (Table 6). The $10 \%$ value occurred during a time when the crater temperature distribution was disturbed by the near-midnight cold-air intrusion. The $75 \%$ contribution was at 0500 LST when winds in the crater were weak (Fig. 10) and the total cooling rate had reached low values that are typical of the end of the night. In the early evening (1700-2200 LST), longwave radiative cooling within the basin contributed roughly one-third of the total observed cooling rate. Averaged over the entire night, longwave radiative cooling contributed $28.5 \%$ of the observed total cooling (Table 6 ).

The vertical profiles of simulated radiative cooling rates and the observed temperature tendencies are shown for 1500, 1900, and 0500 MST in Fig. 11 (0500 MST was chosen instead of 0600 MST to eliminate influences of postsunrise warming). The daytime radiative heating rate at 1500 MST amounts to $42 \%$ of the total heating rate. In the upper part of the crater topography (above $50 \mathrm{~m} \mathrm{AGL}$ ), the two curves match well, showing a slight decrease in radiative and observed heating rates with height. Below $50 \mathrm{~m}$, radiative heating rates exceeded the observed heating rates: the model indicates a strong near-surface heating rate $\left(60 \mathrm{~K} \mathrm{day}^{-1}=2.5 \mathrm{~K} \mathrm{~h}^{-1}\right)$ that quickly drops off to $15 \mathrm{~K} \mathrm{day}^{-1}$ at $50 \mathrm{~m}$ whereas the observed heating rates are variable.

In the early evening (1900 MST), the observed total cooling rates were substantial, with the strongest cooling rates $\left(\sim 80 \mathrm{~K} \mathrm{day}^{-1}\right)$ near the surface, dropping to $30 \mathrm{~K} \mathrm{day}^{-1}$ at $50 \mathrm{~m}$. Above $50 \mathrm{~m}$, cooling rates were constant at $25 \mathrm{~K}$ day $^{-1}$ up to $150 \mathrm{~m}$, dropping to $10 \mathrm{~K}$ day $^{-1}$ at the height of the crater rim. The simulated radiative cooling rates at 1900 LST explained $30 \%$ of the observed basin-average cooling rates but did not show the pronounced profile structure seen in the total cooling but rather showed a height-independent cooling rate of about $10 \mathrm{~K} \mathrm{day}^{-1}$.

The presunrise (0500 MST) profiles of radiative and observed heating rates matched very well, with the exception of the uppermost part of the basin. Both the observed total heating rate and the radiative heating rate were weakly positive near the ground and shifted to a maximum cooling (heating rate of $-15 \mathrm{~K} \mathrm{day}^{-1}$ ) at $20 \mathrm{~m}$ AGL. Above, they increased slowly with height to $-5 \mathrm{~K} \mathrm{day}^{-1}$ at $100 \mathrm{~m}$. Whereas the radiative heating rate predicted by the model increased further to $0 \mathrm{~K} \mathrm{day}^{-1}$, a slight warming $\left(10 \mathrm{~K} \mathrm{day}^{-1}\right)$ was seen in the observations. Nevertheless, $75 \%$ of the observed basin-average heating rate could be attributed to radiative heating, 
TABLE 6. Modeled basin-average radiative heating rate and observed basin-average total heating rate, and the simulated radiative heating-rate contribution (\%) for the Meteor Crater basin during the night of 22/23 Oct 2006.

\begin{tabular}{lccc}
\hline \hline $\begin{array}{c}\text { Time } \\
(\text { LST })\end{array}$ & $\begin{array}{c}\text { Basin-avg radiative } \\
\text { heating rate } \\
\left(\text { K day }^{-1}\right)\end{array}$ & $\begin{array}{c}\text { Obs basin-avg } \\
\text { heating rate } \\
\left(\mathrm{K} \mathrm{day}^{-1}\right)\end{array}$ & $\begin{array}{c}\text { Radiative } \\
\text { contribution to obs } \\
\text { heating rate }(\%)\end{array}$ \\
\hline 1700 & -4.2 & -13.0 & 32 \\
1800 & -7.4 & -18.1 & 41 \\
1900 & -8.3 & -27.4 & 30 \\
2000 & -7.7 & -22.7 & 34 \\
2100 & -6.2 & -35.2 & 18 \\
2200 & -6.0 & -22.1 & 27 \\
2300 & -5.2 & -36.5 & 14 \\
0000 & -3.4 & -35.6 & 9 \\
0100 & -3.1 & -17.7 & 18 \\
0200 & -2.9 & -15.0 & 19 \\
0300 & -1.9 & -13.7 & 14 \\
0400 & -2.3 & -5.9 & 39 \\
0500 & -3.3 & -4.4 & 75 \\
Mean & -4.8 & -20.6 & 28.5 \\
\hline
\end{tabular}

indicating a dominant role of radiative processes in the presunrise hours.

The values of total observed and simulated longwave radiative heating rates given in Table 6 were-under the assumption that they were representative for a full hour-used to calculate the accumulated contribution of radiative cooling to the accumulated observed cooling during the course of the night (Fig. 12). Early in the night, the radiative contribution to accumulated basin cooling is about $30 \%$. After $12 \mathrm{~h}$, however, when the accumulated basin-averaged temperature change exceeded $-11 \mathrm{~K}$, the nighttime radiative cooling contribution is reduced to $22 \%$. This illustrates that, although the largest percentage of instantaneous cooling that can be attributed to radiation is in the early morning hours, the radiative contribution to nighttime cooling is most substantial in the first few hours after sunset.

\section{Discussion}

Our model simulations evaluated the effects of basin shape, type, and size as well as the influence of the nearsurface temperature structure on the basin-average radiative cooling and heating rates. The simulations also resolved the spatial distribution of radiative heating and cooling within the different topographic depressions. Differences between the heating rates seen in the center of a basin and those closer to the basin sidewalls can be large. When no surface-air temperature contrasts exist, the basin-center heating-rate profile quickly approaches the flat-terrain profile when the basin is widened, but the basin-average heating rates were, nonetheless, still clearly affected by the interaction of the radiation field and the basin sidewalls. This shows that one-dimensional radiative transfer models are not suited for investigating radiative heating rates within complex topography.

One of the more striking findings is the importance of the near-surface temperature structure on radiative heating rates in valleys and basins. This finding follows previous studies for flat terrain that have stressed the important influence of the near-surface temperature field (Räisänen 1996; Hoch 2005; Savijärvi 2006). Nearground, terrain-following stable and superadiabatic layers are common in complex terrain, and the study presented here shows the importance of resolving them in the radiative transfer model. Our simulations (Fig. 6) showed that the influence of the near-surface temperature

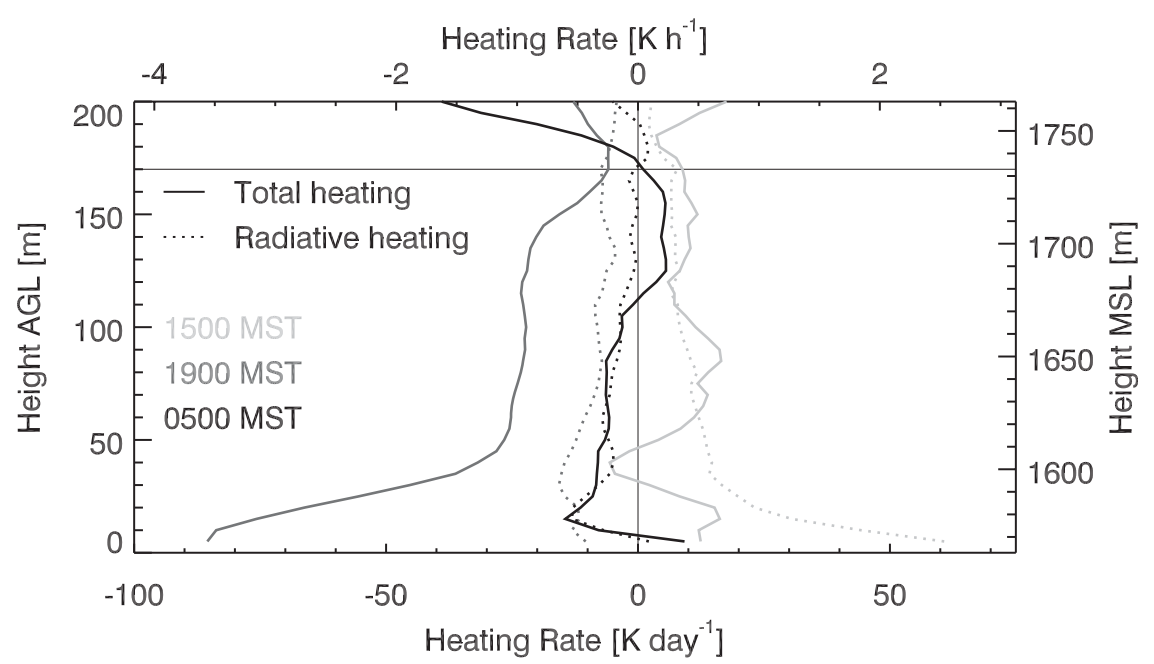

FIG. 11. Total heating (from observations; solid lines) and radiative heating profiles modeled with MYSTIC (dotted lines) for Meteor Crater for 1500, 1900, and 0500 MST 22/23 Oct 2006. 


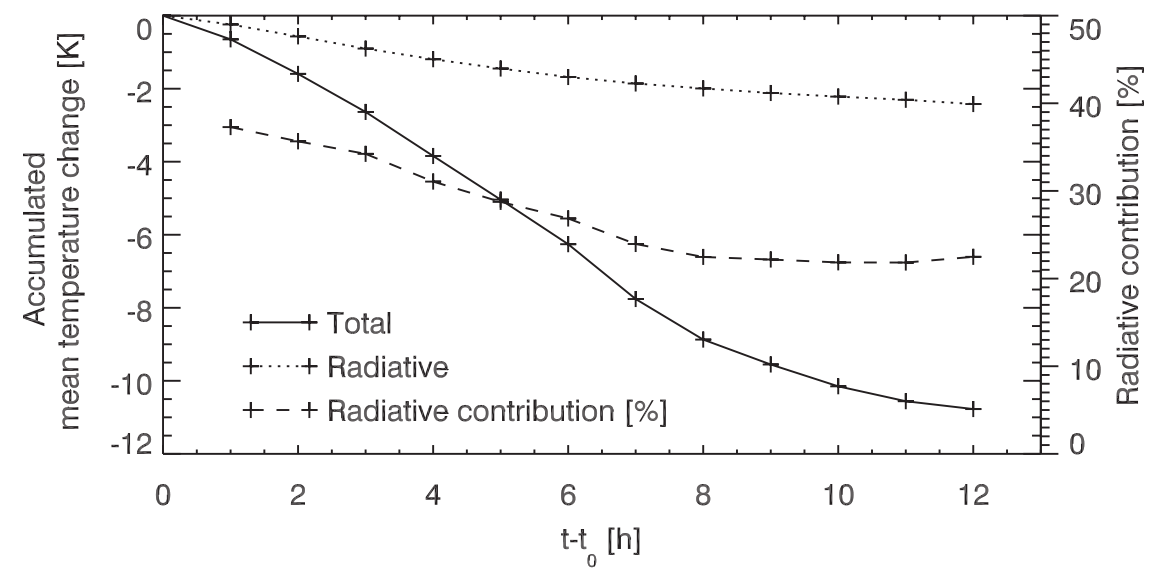

FIG. 12. Accumulated observed total heating (solid line), as calculated from a sequence of atmospheric temperature profiles, and simulated basin-average longwave radiative heating (dotted line) after $t_{0}=1700 \mathrm{MST}$ for Meteor Crater on 22/23 Oct 2006. The dashed line shows the percentage of the total observed cooling that is attributed to radiative transfer (right axis label).

structure exceeded the influence of basin size and shape. In the absence of air-ground temperature differences, basin-average heating rates did not vary greatly with basin size or shape: the maximum variation from the mean was $6.5 \%, 7.7 \%$, and $11.4 \%$ for the three selected times $(1500,1900$, and 0600 LST, respectively). The prescription of a given near-surface temperature difference modulates the influence of topography size: strong increases in radiative heating are seen when the size of a basin is reduced for the 1500 LST case with a realistic superadiabatic layer of $10-\mathrm{K}$ strength. In a similar way, a reduction in basin size will strongly influence the cooling in a basin with a stable near-surface temperature stratification (Fig. 7).

Basin-average heating rates for the 1500 LST simulations in Fig. 7a approach the flat-terrain results as valley and basin widths increase, but this is not the case for the 1900 and 0600 LST simulations in Figs. 7b and 7c. In the 1500 LST case, radiative heating is entirely caused by the overheated ground, and this near-surface heating becomes less important for the basin-average heating as the basin size increases. On the other hand, the situation at 1900 LST is more complex, and we can think of the basin-average radiative cooling as coming from two contributions. The first contribution comes from the nearsurface cooling related to the temperature deficit at the surface. This contribution (similar to that of near-surface heating in the 1500 LST case) decreases with basin size since a larger fraction of the basin volume then becomes farther from the sidewalls. The second contribution to basin-average radiative cooling is the cooling related to the general temperature stratification in the basin. In the 1900 LST case, this is the strong cooling at $50 \mathrm{~m}$ AGL associated with the top of the inversion layer. This contribution, which is reduced by back radiation from nearby basin and valley sidewalls, increases with basin size (Fig. 3, bottom; Table 3). For our combinations of topographies, atmospheric profiles, and surface conditions, the first contribution to basin-average cooling (due to near-surface cooling) is more sensitive to valley and basin width than is the second contribution (due to the general temperature stratification). This results in the smaller differences in basin-average radiative cooling between smaller basins and flat terrain and can even lead to basin-average cooling exceeding that over flat terrain, as seen for the 500-m-wide basin at 0600 LST (Fig. 7c).

Previous studies also accounted for near-surface temperature deficits. In their study of the Aizo basin, Kondo et al. (1989) neglected heated or cooled sidewall surfaces and assumed that radiative cooling would be horizontally uniform, resulting in an overestimation of the basin-average cooling. They assumed an air-surface temperature difference of $-2 \mathrm{~K}$ at night and $5 \mathrm{~K}$ during the day when estimating radiative fluxes at the basin bottom, however. Kyle (1986) set the temperatures of valley sidewalls to be colder by $1-5 \mathrm{~K}$ than the (isothermally stratified) air within a V-shaped valley and reported an increased cooling in valleys relative to flat topography. When relating the cooling within the valleys with colder sidewalls to cooling over flat terrain without a temperature contrast near the ground, Kyle's results are consistent with our calculations. In addition, Kyle found that $10 \%-20 \%$ of the nighttime cooling in the Brush Creek Valley could be attributed to radiative cooling, whereas we find that radiative cooling can account for $28.5 \%$ of the observed cooling in Arizona's Meteor Crater averaged over a night (1700-0500 LST). 
In their study, McKee and Whiteman (1977) primarily addressed the radiative fluxes at the center of the floor of a flat-bottomed, idealized mountain valley. They found that radiation from the sidewalls decreases net radiation loss at the valley floor. They did not calculate fluxes at other levels but speculated that radiative cooling rates in valleys would not differ significantly from flat terrain, although slight changes would occur in both upward and downward longwave fluxes. In contrast, our calculations show that cooling within basins is reduced when compared with flat terrain, unless strong near-surface cooling related to strong inversions over the basin sidewalls dominates the basinwide cooling.

Our study focused solely on the contribution of longwave radiative heating and cooling to the overall temperature evolution in topographic depressions. Other important processes, such as shortwave radiative heating, advection, and sensible and latent heat flux divergences are not discussed in detail. By prescribing representative atmospheric profiles, we include all interacting processes, because they all affect the temperature structure and its evolution and are thus inherent to the profiles. Radiative heating rates that were computed from these profiles are not used to predict the next profile. Rather, instantaneous radiative heating rates are compared with observed heating rates to determine the role of radiative processes relative to all processes affecting the evolution of the temperature profile.

Atmospheric profiles observed in Rocky Mountain valleys were used as input for all of the different topographic shapes, forms, and sizes. These profiles may not be representative for all valleys and basins. Further, we used surface temperature deficits and excesses that were observed in the semiarid Meteor Crater basin of northern Arizona. Less extreme superadiabatic sublayers are expected for terrain with higher surface moisture availability when a greater part of the available energy at the surface is transferred into latent heat. In a similar way, the use of a single mean value for the temperature excess over the entire basin surface is problematic for our daytime calculations. Differential insolation (Hoch and Whiteman 2010) is expected to lead to large differences in the strength of near-surface superadiabatic sublayers and, thus, to strong differences in radiative heating above differently oriented sidewalls. Nevertheless, we think that the atmospheric profiles and the values chosen for the near-surface temperature variations represent realistic conditions. The use of a fixed and limited set of atmospheric profiles was necessary to allow the systematic investigation of the influences of specific characteristics on radiative heating and cooling rates, such as basin size and shape. In the second part of our analysis, when evaluating the relative importance of radiative effects to overall heating and cooling rates, we chose a real basin (Arizona's Meteor Crater) and actual observed boundary conditions to eliminate potentially unrealistic conditions.

\section{Summary and conclusions}

For the first time, quantitative estimates of longwave radiative heating and cooling contributions to the overall temperature evolution within a variety of topographic depressions are available through calculations with the MYSTIC three-dimensional radiative transfer model. The model was used to identify the influences of basin shape and size, as well as inversion and superadiabatic sublayers adjacent to the basin slopes, on radiative cooling rates.

In topographic depressions of 500-m depth and widths between 500 and $5000 \mathrm{~m}$, nighttime cooling is reduced by back radiation from the sidewalls. Early nighttime (1900 LST) radiative cooling, for example, is reduced to $44 \%-58 \%$ of the value seen over flat terrain (assuming no inversion layers on the slopes). Radiative cooling rates above the center of a topographic depression, however, reach the values seen over flat terrain when the distance to the sidewalls exceeds $\sim 2 \mathrm{~km}$.

The variation of the shape of the topographic depression (sinusoidal or witch of Agnesi) has only a minor influence on the strength of radiative heating and cooling, and the differences between a valley and a full circular basin can be more important than size scale. For example, it takes a valley of a size of less than $1 \mathrm{~km}$ to match the radiative cooling rate seen in a $5-\mathrm{km}$-wide circular basin.

Near-surface superadiabatic and stable layers that form along horizontal and inclined surfaces are shown to be key factors influencing radiative heating and cooling rates. Radiative heating and cooling related to the nearsurface temperature profile can influence the atmosphere several tens of meters above. In complex terrain they are more important than the size and shape of the topographic depression.

Calculations of longwave radiative heating and cooling for Arizona's Meteor Crater and comparisons with observed temperature evolution within this basin during a calm night reveal that radiative transfer plays an important role in the diurnal temperature evolution within topography. The radiative contribution amounts to about $30 \%$ of the overall nocturnal cooling in Meteor Crater but can reach $75 \%$ in the hours just before sunrise.

Acknowledgments. SWH was supported by Grant 52734-EV from the Army Research Office. CDW was supported by National Science Foundation Grants ATM-0444205 and ATM-0837870. We thank those listed 
in the acknowledgments section of Whiteman et al. (2008) for their help with the field program.

\section{REFERENCES}

Cahalan, R., and Coauthors, 2005: The I3RC: Bringing together the most advanced radiative transfer tools for cloudy atmospheres. Bull. Amer. Meteor. Soc., 86, 1275-1293.

Emde, C., and B. Mayer, 2007: Simulation of solar radiation during a total solar eclipse: A challenge for radiative transfer. Atmos. Chem. Phys., 7, 2259-2270.

Haiden, T., C. D. Whiteman, S. W. Hoch, and M. Lehner, 2011: A mass-flux model of nocturnal cold air intrusions into a closed basin. J. Appl. Meteor. Climatol., 50, 933-943.

Hoch, S. W., 2005: Radiative flux divergence in the surface boundary layer. A study based on observations at Summit, Greenland. Ph.D. thesis, ETH, 164 pp. [Available online at http://e-collection. library.ethz.ch/eserv/eth:28552/eth-28552-02.pdf.]

_ and C. D. Whiteman, 2010: Topographic effects on the surface radiation balance in and around Arizona's Meteor Crater. J. Appl. Meteor. Climatol., 49, 1114-1128.

Kondo, J., T. Kuwagata, and A. Haginoya, 1989: Heat budget analysis of nocturnal cooling and daytime heating in a basin J. Atmos. Sci., 46, 2917-2933.

Kondratyev, K. Ya., 1969: Radiation in the Atmosphere. International Geophysics Series, Vol. 12, Academic Press, 912 pp.

Kyle, T. G., 1986: Radiative cooling in valleys and hollows. Comput. Geosci., 5, 697-703.

, 1987: The energy budget in a valley nocturnal flow. Tellus, 39A, 226-234.

Mayer, B., 2009: Radiative transfer in the cloudy atmosphere. Eur. Phys. J. Conf., 1, 75-99.

_ , and A. Kylling, 2005: The libRadtran software package for radiative transfer calculations: Description and examples of use. Atmos. Chem. Phys., 5, 1855-1877.
S. W. Hoch, and C. D. Whiteman, 2010: Validating the MYSTIC three-dimensional radiative transfer model with observations from the complex topography of Arizona's Meteor Crater. Atmos. Chem. Phys., 10, 8685-8696.

McKee, T. B., and C. D. Whiteman, 1977: Components of infrared net radiation in a mountain valley. Colorado State University Dept. of Atmospheric Sciences Atmospheric Science Paper 279 (Climatology Rep. 77-5), 101 pp.

Räisänen, P., 1996: The effect of vertical resolution on clear-sky radiation calculations: Tests with two schemes. Tellus, $\mathbf{4 8 A}$, 403-423.

Savijärvi, H., 2006: Radiative and turbulent heating rates in the clearair boundary layer. Quart. J. Roy. Meteor. Soc., 132, 147-161.

Stamnes, K., S. Tsay, W. Wiscombe, and K. Jayaweera, 1988: A numerically stable algorithm for discrete-ordinate-method radiative transfer in multiple scattering and emitting layered media. Appl. Opt., 27, 2502-2509.

Whiteman, C. D., 1980: Breakup of temperature inversions in Colorado mountain valleys. Colorado State University Dept. of Atmospheric Sciences Atmospheric Science Paper 328, $250 \mathrm{pp}$.

— C. B. Clements, and J. D. Horel, 2002: Turbulent and radiative flux divergence in cold pools that form within a highelevation basin. Preprints, 15th Symp. on the Boundary Layer and Turbulence, Wageningen, Netherlands, Amer. Meteor. Soc., 662-665.

, and Coauthors, 2008: METCRAX 2006. Meteorological experiments in Arizona's Meteor Crater. Bull. Amer. Meteor. Soc., 89, 1665-1680.

_ S. W. Hoch, M. Lehner, and T. Haiden, 2010: Nocturnal coldair intrusions into a closed basin: Observational evidence and conceptual model. J. Appl. Meteor. Climatol., 49, 1894-1905.

Zinner, T., A. Marshak, S. Lang, J. V. Martins, and B. Mayer, 2008: Remote sensing of cloud sides of deep convection: Towards a three-dimensional retrieval of cloud particle size profiles. Atmos. Chem. Phys., 8, 4741-4757. 